\title{
21 hypoglycemia cases with hyperinsulinemia
}

\author{
Yusuke Mizuno ${ }^{*}$, Satsuki Nishigaki, Kengo Miyashita, Akiko Yamamoto, Yasuhiro Naiki, Reiko Horikawa \\ From 7th APPES Biennial Scientific Meeting \\ Nusa Dua, Bali. 14-17 November 2012
}

Congenital hyperinsulinemic hypoglycemia $(\mathrm{CHI})$ is the common cause of severe hypoglycemia in infancy. Profound hypoglycemia requires appropriate diagnosis and aggressive treatment to prevent severe and irreversible brain damage. Here we report 21 Japanese hypoglycemia cases with severe hyperinsulinemia.

We report $16 \mathrm{CHI}$ cases, 2 HIHA cases, 1 GSD1b case and 2 PSS cases. 12 cases of $\mathrm{CHI}$ had severe episodes of cardiac arrest or seizure in neonatal period, 3 cases of $\mathrm{CHI}$ had seizure in infancy, 1 case of $\mathrm{CHI}$ had hypoglycemia in infancy. Neonatal-onset $\mathrm{CHI}$ cases were treated by octreotide and glucagon at the start. 4 cases of $\mathrm{CHI}$ ( 3 of them had KCNJ11 mutation) were treated as diabetes after pancreatic excision. We will perform pancreatic partial excision to 1 case of $\mathrm{CHI}$ who had paternal mutation of $\mathrm{ABCC} 8.1$ case of $\mathrm{CHI}$ with $\mathrm{ABCC} 8$ mutation is on good control by only diet therapy. We stopped the treatment by diazoxide to 4 cases of $\mathrm{CHI}$ until 10 years old. Acuity of the them was varied on the onset. 5 cases of $\mathrm{CHI}$ is still treated by diazoxide. HIHA cases had seizure in infancy. They are on good control by diazoxide. GSd1b case had severe hypoglycemia in neonatal period. He was treated as $\mathrm{CHI}$ patient by diazoxide. He was diagnosed as GSd1b by hepatomegaly. After live-donor liver transplant, he is on the good control without medicaton. 1 of PSS cases had hypoglycemia in babyhood. He was cured by surgery. 1 of PSS cases had severe hypoglycemia attack in neonatal period. His family did not choose surgery, so he is still treated by diazoxide.

Three-quarter of $\mathrm{CHI}$ cases had severe hypoglycemic attack in neonatal period. Some cases needed surgery, some cases could be controlled by internal therapy and could be cured. 5 cases had hyperinsulinemia except $\mathrm{CHI}$ cases. Some cases showed hyperammonemia except HIHA. Correct diagnosis for hypoglycemia cases with

Division of endocrinology and metabolism, National Center For Child Health and Development, Japan hyperinsulinemia needs not just blood test but also imaging or genetic testing.

Published: 3 October 2013

doi:10.1186/1687-9856-2013-S1-P177

Cite this article as: Mizuno et al:: 21 hypoglycemia cases with 2013(Suppl 1):P177.

Submit your next manuscript to BioMed Central and take full advantage of:

- Convenient online submission

- Thorough peer review

- No space constraints or color figure charges

- Immediate publication on acceptance

- Inclusion in PubMed, CAS, Scopus and Google Scholar

- Research which is freely available for redistribution hyperinsulinemia. International Journal of Pediatric Endocrinology 2013 